\title{
DEMOCRACIAS POSIBLES: CRISIS Y RESIGNIFICACIÓN. SUR DE MÉXICO Y CENTROAMÉRICA. COORDINADORES: MARÍA DEL CARMEN GARCÍA AGUILAR, JESÚS SOLÍS CRUZ Y PABLO UC. TUXTLA GUTIÉRREZ, CHIAPAS: UNIVERSIDAD DE CIENCIAS Y ARTES DE CHIAPAS (UNICACH), 2016
}

Jorge Rovira Mas

\author{
Recibido: 09/07/2017 Aceptado: 17/07/2017
}

Este libro es un producto del trabajo académico que ha venido desarrollando el Observatorio de las Democracias: sur de México y Centroamérica (ODEMCA), localizado en el Centro de Estudios Superiores de México y Centroamérica (CESMECA, 1995), en San Cristóbal de las Casas (Chiapas, México), una instancia de investigación y posgrado de la Universidad de Ciencias y Artes de Chiapas (UNICACH, 1944). El CESMECA, entidad hasta el presente poco conocida en el sur centroamericano, ha venido desplegando diversas actividades que la posicionan y visibilizan cada día más en el ámbito académico regional e internacional.

El libro es también el fruto de nuevas generaciones de académicos, mexicanos y centroamericanos principalmente, muy bien formados, que viven, sienten, observan, analizan y critican el nuevo escenario social dentro del cual se despliegan sus biografías. Valga decir: esa realidad que ha ido emergiendo y constituyéndose contradictoriamente a partir de dos conjuntos de procesos/eventos.

El primero de ellos, la institucionalización de las democracias electorales devenidas en Centroamérica tras la crisis política de los años ochenta del siglo XX y los Acuerdos de Paz de los noventa (1992 en El Salvador y 1996 en Guatemala). En concomitancia con lo anterior, la aparición del Ejército Zapatista de Liberación Nacional en el sur de México, en Chiapas, desde 1994, y entonces el Movimiento Zapatista, con su arraigo y vocación de construir nuevas instituciones sociales y políticas desde sus bases populares.

Los segundos procesos/eventos, característicos de la globalización en curso, son los nuevos entornos socioeconómicos fraguados a lo largo de dos décadas de operación del Tratado de Libre Comercio de Norteamérica (TLCAN, 1994), por un lado, y con la entrada en vigencia del Tratado de Libre Comercio entre República Dominicana, Centroamérica y Estados Unidos (TLC, del 2006 al 2009 según los países), por otro. Esto último como un resultado de la hegemonía alcanzada por el neoliberalismo en la región, tanto en su perfil ideológico como también en la manufactura de las prácticas socioeconómicas prevalecientes. 
La obra se encuentra vertebrada alrededor de dos ejes capitales: la crítica teórica de la democracia liberal, que se acompaña con la reflexión en torno a "otras democracias posibles", y la muestra de prácticas concretas que son ejemplos de estas. De hecho, dichos ejes constituyen las temáticas abordadas por diferentes trabajos en la "Primera parte: Debate teórico" y en la "Tercera parte: Democracias otras". La "Segunda parte: Centroamérica y México" está dedicada más bien al análisis de dinámicas sociopolíticas recientes en Guatemala, Honduras, El Salvador, Chiapas y Yucatán.

Las contribuciones incluidas son catorce: tres en la primera parte, ocho en la segunda $y$, por fin, otras tres en la tercera, a lo que se suma una introducción y una suerte de epílogo o reflexiones finales, ambos escritos por los tres coordinadores del libro: María del Carmen García Aguilar, Jesús Pablo Solís Cruz y Pablo Uc. En total, son dieciocho los contribuyentes, provenientes de México, Costa Rica, Guatemala, El Salvador, Chile, Colombia y Alemania.

Desde mi punto de vista, son particularmente interesantes los artículos incluidos en la primera y en la tercera parte. Es decir, allí donde se disputa el paradigma normalizado o hegemónico para comprender y analizar la democracia entendida como democracia liberal, representativa, esencialmente procedimental, electoral, y sus enfoques recientes que han venido adquiriendo una aceptación extendida: los relativos a la transición a la democracia y su consolidación.

En la "Primera parte" tenemos la contribución de Laura Álvarez Garro, titulada "Debate teórico en torno a la democracia: del concepto hegemónico a las otras democracias". Anclada en planteamientos del autor francés Derrida, culmina su texto insistiendo en que "una 'democracia por-venir' que pretenda aparecer en el aquí y en el ahora no debe responder a una única forma, sino que debe estar fundamentalmente abierta... Al hacer eco del planteamiento derridiano, queremos proponer una democracia que se mire desde su carácter histórico-social, abierta a nuevas formas de organización, pero sin anquilosar ninguna de éstas" (47).

Por su parte, María del Carmen García Aguilar, "Pensamiento y realidad de la democracia liberal en tiempos de globalización neoliberal. A propósito de México y Centroamérica", se centra en la contradicción entre la presunta democratización en curso de esta parte de América y el marco de globalización económica dentro del cual es que se aspira a institucionalizarla y hacerla funcionar. Un marco generador de pobreza, desigualdad y violencia, que dificulta, cuando no es que impide, la constitución de la subjetividad propia de las ciudadanías, mediante la cual se reconocen y ejercen sus derechos, y que consecuentemente se inclinarían por una afirmación positiva de la democracia tanto en su discurso como en sus prácticas institucionalizadas. La autora se refiere entonces a esto como desdemocratización. Esta vendría a ser el resultado de "la subordinación de la democracia política al proyecto global neoliberal, proyecto que altera en conjunto los vectores de la democracia liberal, el Estado, la economía y la sociedad" (60). 
El tercero de los trabajos de dicha primera parte es el de Pablo Uc, "Perspectivas contra hegemónicas de la democracia: discursos y prácticas otras de lo político y lo democrático". Este joven autor se decanta en primera instancia por la postulación de Boaventura de Sousa Santos de la demo-diversidad. Se trata de "la coexistencia de diversos formatos de democracia en un contexto histórico determinado. Formas de democracia que desbordan la fórmula liberal representativa, fundamentadas en la creatividad de iniciativas populares -institucionalizadas o no-, participativas y comunitarias, bajo la apuesta de no subordinarse unas a otras" (79). Un asunto cardinal dentro de esta mirada es el de "la autonomía en clave no estatal" (90).

Los tres trabajos incorporados en la tercera parte del libro ("Democracias otras") son diferentes a lo habitual que se encuentra en las publicaciones que aparecen en Centroamérica: dos de ellos dedicados a la narrativa y al análisis sobre experiencias histórico-sociales concretas relativas a prácticas políticas de esas "otras democracias", y uno final de cierre que destaca nuevas perspectivas latinoamericanas sobre la evolución social de esta zona.

Carlos Alonso Reynoso y Jorge Alonso Sánchez son los autores de la contribución titulada "Profundizaciones en torno a la demoeleuthería". Pero, ¿qué significa este concepto de manifiesta raíz griega? Su connotación postulada es la siguiente: "la libertad de los de abajo". Se alude entonces a la "libertad de los de abajo forjadora de autonomía" (281), en contraste con la democracia imperante como democracia de élites que controlan el poder y subordinan a los sectores populares. Se analiza la justicia zapatista y las luchas anticapitalistas del zapatismo, así como la educación para la autonomía, todo ello en clave de transformaciones institucionales y subjetivas. Un texto hermoso y extremadamente sugerente.

Xochitl Leyva Solano y Axel Köhler entregan el trabajo "Las guerras, la otra política y los medios indígenas en movimiento". Se encuentra centrado en el "video activismo maya chiapaneco", en tanto que "arma de lucha en medio de resistencias, movilizaciones y guerras para verlo a contraluz de la evolución de la democracia representativa en Chiapas" (325), siempre en perspectiva de construcción de autonomía. La noción de "medios indígenas" se inspira en el concepto de "medios ciudadanos", planteado por la especialista en comunicación colombiana Clemencia Rodríguez, que lo generó para "redirigir el análisis alejándolo de cualquier comparación con los medios masivos y los medios comerciales, para concentrarse más bien en los procesos culturales y sociales que se desencadenan cuando las comunidades locales se apropian de las tecnologías de información y comunicación" (cita de Rodríguez por los autores en p. 333). Es este texto otro de mucho interés, que invita a conocer el proceso de construcción de nuevos espacios sociales dirigidos a resistir y a producir libertad desde los sectores subordinados de la sociedad.

Arturo Escobar, en el artículo final del libro -previo al epílogo- "Desde abajo, por la izquierda y con la Tierra: la diferencia de Abya Yala/Afro/Latino/América", 
confronta la tesis de que el pensamiento crítico latinoamericano (PCL) se halla en crisis. Tras su propio inventario de la vitalidad que patentiza el PCL hoy ("las críticas a la modernidad y la teoría decolonial; los feminismos autónomos, decoloniales, comunitarios y de mujeres indígenas y afrodescendientes; la diversa gama de debates ecológicos y de economías alternativas, incluyendo la ecología política, la economía social y solidaria, las economías comunales y los comunes; las posiciones autonómicas; otras y nuevas espiritualidades; y las diferentes propuestas de transiciones civilizatorias, interculturalidad, el posdesarrollo, el Buen Vivir y el post-extractivismo", 341). Escobar se centra en dos vertientes en particular: la que denomina "el pensamiento autonómico" y el "pensamiento de la tierra". Concluye, entre otros señalamientos, que quienes "insistan en la vía del desarrollo y la modernidad son o suicidas, o al menos ecocidas, y sin duda históricamente anacrónicos" (p. 353).

Los trabajos de la segunda parte, de los cuales los primeros cinco están centrados en Centroamérica, son estos: el de Daniel Villafuerte Solís que se titula "El Triángulo Norte de Centroamérica: dilemas de la democracia en una subregión conflictiva"; el de Jahir Dabroy, quien nos entrega "Guatemala, ¿hacia un nuevo paradigma de construcción de ciudadanía?"; el de Andrés León, un joven académico costarricense, quien ha enfocado mucho sus investigaciones en Honduras y que nos actualiza sobre la situación política de esta sociedad mediante su artículo "Democracia desde arriba, democracia desde abajo: elecciones, poder y conflicto en Honduras post-golpe de Estado"; el de Carlos Mauricio Hernández, que aborda la competencia electoral salvadoreña desde un ángulo particular, "Mesianismo político en El Salvador: análisis de discurso de los candidatos de ARENA y el FMLN en las campañas electorales presidenciales de 2004 y 2009"; y nuevamente sobre Guatemala -el segundo-, Manuel Ignacio Martínez Espinoza dedica su contribución a un tema de enorme vigencia, “¿Extracciones y consultas? La minería y los derechos de los pueblos indígenas como un mentís de la democracia en Guatemala".

Los tres últimos de esta segunda parte se centran, entonces, más bien en México y los Estados del sureste: Juan Mora Heredia y Margarita Jiménez Badillo contribuyen con "Democracia, confianza y ciudadanía en México"; el de Jesús Solís Cruz es "Chiapas, la democracia que no fue"; y Efraín Eric Poot Capetillo, "Yucatán y el alcance estabilizador de las elecciones convergentes de 2015".

El origen y sustento de este empeño, el balance conseguido, la crítica inspiradora y éticamente comprometida con el develamiento de las injusticias y limitaciones que la democracia actual no ha conseguido reparar, antes bien que en algunos casos ha coadyuvado a mantener o a incrementar, en medio, eso sí, de una mayor conciencia colectiva y una activación de los grupos subalternos de estas sociedades, así como los horizontes de emergencia institucional y de nuevas prácticas democráticas que aquí se describen, hacen de este libro un bien logrado, honesto, interesante, oportuno y muy recomendable producto generacional que convoca a su lectura. 
Jorge Rovira Mas. Costarricense. Doctor en Sociología por la Universidad Nacional Autónoma de México (UNAM, 1980). Profesor de la Universidad de Costa Rica durante los años 1970-2013, cuando se jubiló. Actualmente es Profesor Emérito de esta casa de estudios superiores.

Contacto: jroviramas@gmail.com

ORCID: 0000-0003-0641-8881 
